\title{
Investigating the sensitivity of Venturia inaequalis isolates to difenoconazole and pyraclostrobin in apple orchards in China
}

\author{
Xiancheng Li • Haiyuan Li • Zhen Yu • Liqiang Gao • \\ Jiarong Yang
}

Accepted: 18 June 2021 / Published online: 30 June 2021

(C) The Author(s) 2021

\begin{abstract}
The resistance level of 90 single lesion conidial isolates of Venturia inaequalis collected from multiple commercial orchards in Shaanxi and Gansu Provinces and Xinjiang Autonomous Region of China to the demethylation inhibitor (DMI) fungicide difenoconazole and quinone outside inhibitor (QoI) fungicide pyraclostrobin was examined. The $\mathrm{EC}_{50}$ values of the 90 isolates to difenoconazole and pyraclostrobin ranged from 0.143 to $6.735 \mu \mathrm{g} / \mathrm{mL}$ and 0.084 to $2.026 \mu \mathrm{g} / \mathrm{mL}$, respectively. Among the isolates, 19 had resistance, 66 had reduced sensitivity, and five had sensitivity to difenoconazole; eight had resistance, 81 had reduced sensitivity, and one had sensitivity to pyraclostrobin. Although a weak correlation between difenoconazole and pyraclostrobin was detected, four isolates were identified as resistant to difenoconazole and pyraclostrobin. However, isolates with practical resistance were not found widely in our study and were only sporadic in a few places, indicating that at present, difenoconazole and pyraclostrobin are still safe for disease management in the apple-growing areas of Shaanxi, Gansu and Xinjiang. However, the risk of fungicide resistance should be managed with caution, and yearly monitoring of resistance development is necessary.
\end{abstract}

Keywords Apple scab - Venturia inaequalis .

Difenoconazole $\cdot$ Pyraclostrobin $\cdot$ Fungicide resistance

X. Li $\cdot$ H. Li $\cdot$ Z. Yu $\cdot$ L. Gao $(\bowtie) \cdot$ J. Yang $(\bowtie)$

College of Plant Protection, Northwest A\&F University,

Yangling 712100 Shaanxi, China

e-mail: gaoliqiang@nwafu.edu.cn

e-mail: yjrong@nwsuaf.edu.cn

\section{Introduction}

Apple scab, caused by Venturia inaequalis, mainly damages apple leaves, flowers and fruits. Venturia inaequalis is found in almost all areas in which apples are grown commercially. It is the most important disease of apple worldwide in terms of the economic cost of control (Beresford and Manktelow 1994; MacHardy 1996; Holb et al. 2017). If scab control measures are not taken, the disease may cause $70 \%$ or more losses in fruit value (MacHardy 1996; Holb et al. 2005). In China, apple scab epidemics occurred in Shaanxi apple growing areas in 2000 and caused serious economic losses. There are also reports of this disease in other appleproducing areas in China (Hu et al. 2010). Although apple scab has shown reduced severity in the past few years in Shaanxi, the incidence of apple scab has gradually increased in recent years in Shaanxi, Gansu and Xinjiang. In apple production, fungicides remain the primary tool to control this disease (Jones and Aldwinckle 1990; MacHardy 1996; Holb et al. 2017), especially under moderate climatic conditions, as the ideal conditions for infection and disease progression are $16-20{ }^{\circ} \mathrm{C}$ and the presence of moisture for $6-8 \mathrm{~h}$, as described in Mills tables (MacHardy and Gadoury 1989; Bowen et al. 2011). However, because infection occurs first in older leaves in the lower part of the plants, the conidia can be spread by air currents and rain splash driving further infection (Holb et al. 2003, 2017). Therefore, repeated application of fungicides is required over the course of a single season (MacHardy 1996; Passey et al. 2016), and the correct timing of fungicide 
application is essential for effective control (Beresford and Manktelow, 1994).

Currently, some resistance genes against apple scab used in apple breeding have been overcome by pathogens (Papp et al. 2020; McClure et al. 2018; Khajuria et al. 2018). Fungicide application remains the primary strategy for managing the disease. However, due to the large population of $V$. inaequalis and its rapid multiplication, pathogen populations can rapidly evolve resistance to certain fungicides. Pathogens usually gain fungicide resistance from mutation or recombination. The resulting resistance frequency will be increased through fungicide use via selection pressure and can be transferred to other populations (Angelini et al. 2015). Therefore, practical fungicide resistance is considered to greatly reduce disease control efficiency even if proper fungicide application is performed under field conditions (Köller et al. 1991; Villani and Cox 2014; Holb et al. 2005).

Difenoconazole (a demethylation inhibitor, DMI), approved in 1988 in Europe, has been widely used worldwide in agricultural production due to its broad spectrum, fast effects and systemic activity (Bowyer and Denning 2014). It has both protective and curative effects and is widely used to control soil-borne, foliar and seed diseases (Golembiewski et al., 1995). Although DMI fungicides are considered a medium risk for resistance by the Fungicide Resistance Action Committee (FRAC) (Stenzel 2014), intensive use of DMI fungicides has led to reduced disease control efficacy and induced resistance to some fungicides in several apple production regions (Jobin and Carisse 2007; Köller et al. 1997; Villani and Cox 2011; Cox et al., 2009). Additionally, cross-resistance of $V$. inaequalis isolates has been found among DMI fungicides (Pfeufer and Ngugi 2012), resulting in poor disease control efficacy (Stanis and Jones 1985; Jobin and Carisse 2007).

Pyraclostrobin (a quinone outside inhibitor, QoI), which has a different mechanism than DMI fungicides, is also widely used to control many plant diseases. In addition, it promotes crop health. QoI fungicides were registered for use on apple scab around the beginning of the twenty-first century (Ypema and Gold 1999). A population of $V$. inaequalis that had acquired resistance towards pyraclostrobin was first discovered in Europe (Steinfeld et al. 2002). Among all fungicides used against apple scab, a complete loss of efficacy in practice has been observed only in the case of QoI fungicides (Mondino et al. 2015: Fontaine et al. 2009:
Lesniak et al. 2011), and pyraclostrobin is considered high risk for resistance by the FRAC (Stenzel 2014).

At present, the management of apple scab in China mainly involves difenoconazole and pyraclostrobin. In addition, these two fungicides are also used to control Valsa canker (Valsa mali), Marssonina apple blotch (Marssonina coronaria), apple bitter rot (Colletotrichum spp.) and apple rust (Gymnosporangium yamadai Miyabe) (Junfei et al. 2012; Feng et al. 2020). With the extensive and abundant use of these two fungicides, the potential risk of developing fungicide resistance is worrying even if there is no such report of $V$. inaequalis resistance towards these two fungicides.

Knowledge of fungicide resistance in pathogen populations is important to provide a basis for disease control strategies. To date, the prevalence of resistance to these two fungicides in a population of $V$. inaequalis in Northwest China is not well understood. Moreover, many apple root stocks and seedlings have been introduced from Europe to apple orchards in Northwest China for decades. It is unclear whether a population of fungicide-resistant isolates could be introduced from Europe to these areas. In recent years, apple scab in Northwest China has worsened yearly, and disease control efficacy has not been good with the use of these two fungicides. It is likely that the emergence of a fungicideresistant population of $V$. inaequalis in apple orchards could lead to a decline in apple scab control. Therefore, the goals of this study were to: (i) investigate whether $V$. inaequalis isolates from Northwest China exhibit difenoconazole and pyraclostrobin resistance; (ii) evaluate the level, frequency and distribution of strains resistant to the two fungicides; and (iii) examine whether there is cross resistance between the two fungicides.

\section{Materials and methods}

\section{Collection and isolation of $V$. inaequalis}

Samples of apple scab were collected in Qianyang, Fufeng and Qianxian counties of Shaanxi Province; in Pingliang, Huining, Jingning, Lixian and Zhuanglang counties of Gansu Province; and in Yining, Tekesi and Gongliu counties of the Xinjiang Autonomous Region (Table 1 and Fig. 1). Between the counties, the collection sites were more than $100 \mathrm{~km}$ apart, and within each county, sampled apple orchards were at least $1000 \mathrm{~m}$ 
Table 1 Ninety isolates of Venturia inaequalis collected in various geographical origins

\begin{tabular}{|c|c|c|}
\hline Region & County & Isolate code \\
\hline \multirow[t]{3}{*}{ Shaanxi } & Qianyang & $\begin{array}{l}\text { SX-GL12 SX-GL15 SX-GL17 SX-GL36 SX-GL4 SX-GL44 SX-GL45 } \\
\text { SX-GL46 SX-JG10 SX-JG12 SX-JG17 SX-JG25 } \\
\text { SX-FK1 SX-FK11 SX-FK12 }\end{array}$ \\
\hline & Fufeng & SX-Jiu2 SX-Jiu12 SX-Jiu13 SX-Jiu18 SX-Jiu23 SX-Jiu25 \\
\hline & Qianxian & SX-PL24 SX-PL28 SX-PL30 SX-PL32 SX-PL35 SX-PL37 SX-PL40 SX-PL64 SX-PL67 \\
\hline \multirow[t]{5}{*}{ Gansu } & Jingning & $\begin{array}{l}\text { GS-SF2 GS-SF3 GS-SF5 GS-SF6 } \\
\text { GS-SF7 GS-Jona2 GS-Jona3 GS-Jona5 }\end{array}$ \\
\hline & Huining & GS-M26\2 GS-M2615 GS-M26\6 GS-M26\7 GS-M26\8 \\
\hline & Lixian & GS-a3 GS-a31 GS-J1 GS-J4 GS-J9 GS-J16 \\
\hline & Zhuanglang & GS-HF1 GS-HF2 GS-HF2A GS-HF3 GS-HF4 GS-HF5 GS-HF6 GS-HF14 \\
\hline & Pingliang & GS-YF5 GS-YF7 GS-YF15 \\
\hline \multirow[t]{3}{*}{ Xinjiang } & Yining & $\begin{array}{l}\text { XJ-HH1 XJ-HH4 XJ-HD4 XJ-HD5 } \\
\text { XJ-HD6 XJ-HD8 }\end{array}$ \\
\hline & Gongliu & $\begin{array}{l}\text { XJ-LX3 XJ-LX4 XJ-LX6 XJ-n1 } \\
\text { XJ-Lv1 XJ-Lv2 XJ-Lv3 XJ-Lv4 } \\
\text { XJ-Lv6 }\end{array}$ \\
\hline & Tekesi & $\begin{array}{l}\text { XJ-HC2 XJ-HC3 XJ-HC4 XJ-HC6 } \\
\text { XJ-HC7 XJ-HC8 XJ-HC9 XJ-HC10 XJ-HC11 XJ-HC12 XJ-HC13 } \\
\text { XJ-HC14 XJ-HC17 XJ-HC18 XJ-HC19 }\end{array}$ \\
\hline
\end{tabular}

apart. Young, fully expanded leaves with typical new sporulating apple scab lesions were collected in orchards. For each infected tree, 10 leaves were collected for fungal isolation and considered one sample. A corkborer $0.5 \mathrm{~cm}$ in diameter was used to cut a disc from each leaf, ensuring that a lesion was present in the disc.

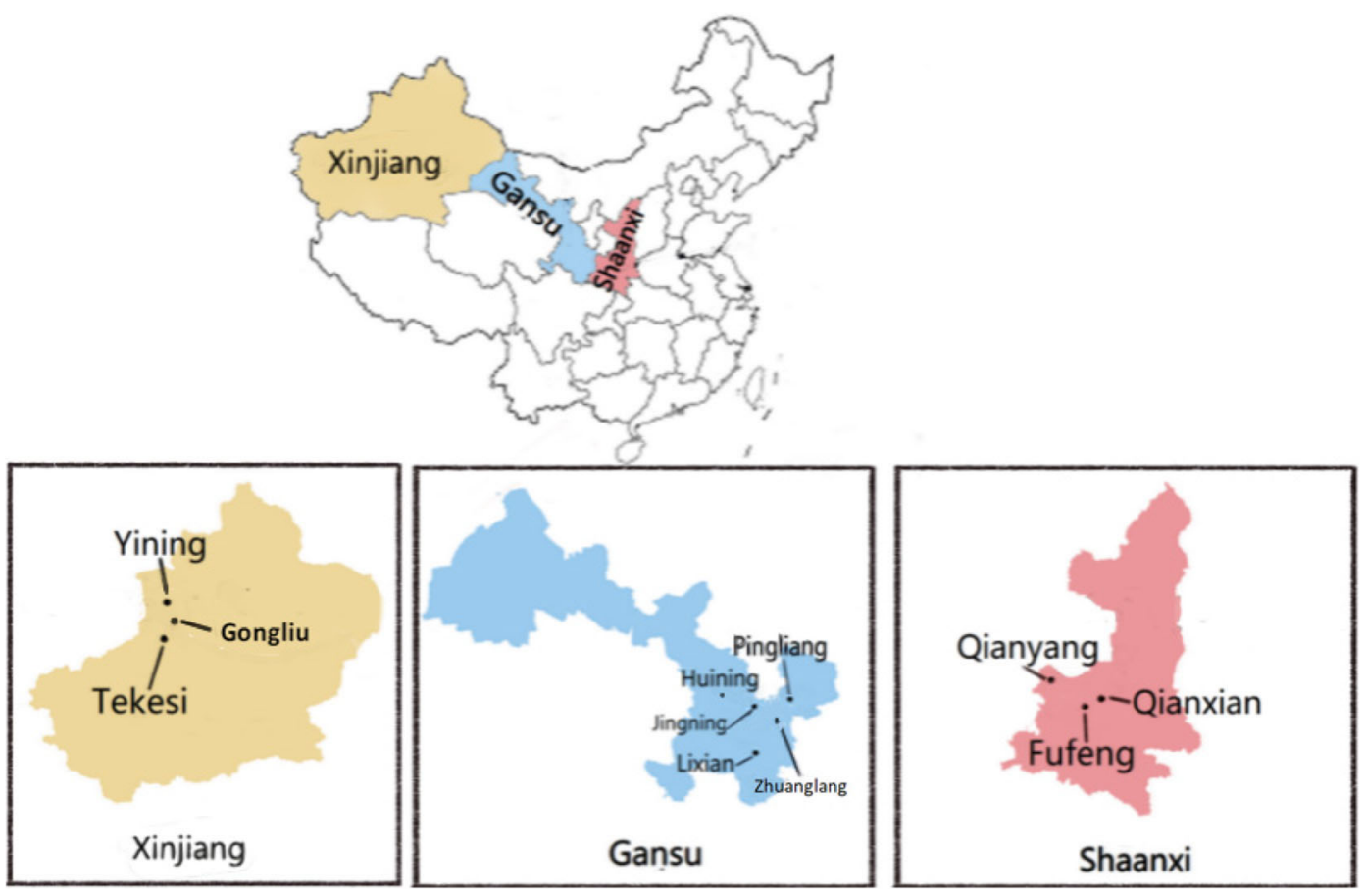

Fig. 1 Three apple growing regions of Shaanxi, Gansu and Xinjiang and areas where apple scab sample collection was carried out 
Each disc was transferred to a microcentrifuge tube, air dried at room temperature, and stored at $-20{ }^{\circ} \mathrm{C}$. Water agar $\left(15 \mathrm{~g} \mathrm{l}^{-1}\right)$ was used to obtain single-spore isolates. Sterilized distilled water $(1.5-2 \mathrm{ml})$ was added to the microcentrifuge tube, which contained an infected leaf disc and was agitated thoroughly. Approximately $200 \mu \mathrm{l}$ of this suspension was pipetted onto water agar and spread evenly, and then the plates were air-dried in a sterile cabinet and incubated at $18{ }^{\circ} \mathrm{C}$ for $24 \mathrm{~h}$. After approximately $24 \mathrm{~h}$, individual germinated conidia were marked over the petri dish under the microscope. Marked areas were removed with a sterile needle and placed on PDA (potato dextrose agar). The plates were incubated at $20^{\circ} \mathrm{C}$, and each colony was transferred to a fresh PDA plate after 2 to 3 weeks. All isolates collected in Shaanxi, Gansu and Xinjiang were designated according to the cultivar name of the host and sampling location, and their sensitivity to difenoconazole and pyraclostrobin was evaluated.

Difenoconazole and pyraclostrobin sensitivity determination

Difenoconazole and pyraclostrobin sensitivity of $V$. inaequalis isolates was assessed by evaluating mycelial growth on fungicide amended in medium. Technical-grade fungicides were dissolved in acetone and adjusted to stock solutions with 10-fold serial dilution in sterile distilled water. Stock solutions were added to molten PDA to achieve final concentrations of 0.05 , $0.10,0.50$, and $1.00 \mu \mathrm{g} / \mathrm{mL}$ for difenoconazole (Green Chemical Co. LTD, Wenzhou, Zhejiang, China) and $0.02,0.04,0.2$, and 0.4 for pyraclostrobin (Meibang Co. LTD, Weinan, Shaanxi, China) in 9-cm-diameter petri plates. The concentrations were determined according to previous test results (Henríquez Sáez et al. 2011; Villani et al. 2015). Mycelia growing on PDA in the petri plates were used as a source of inoculum. A 5-mm mycelial plug was punched from the edge of the cultured colony with a puncher and transferred to a series of gradient fungicide concentrations in media; each fungicide concentration treatment had three plates and was repeated four times. PDA plates without fungicide were used as a control treatment. After 40 days of incubation at $20{ }^{\circ} \mathrm{C}$, the colony growth diameter was measured twice along perpendicular axes with a caliper, and the average value was determined (excluding the initial plug diameter). Relative growth ( $R G)$ was defined as follows: $\mathrm{RG}=($ mean mycelial expansion in fungicide-amended medium/mean mycelial expansion in control plates) $\times 100(\%)$. Relative inhibition (RI) was defined as $100-\mathrm{RG}(\%)$. The sensitivity was classified according to the following criteria: sensitivity $=$ $\mathrm{RI} \geq 70 \%$, reduced sensitivity $=$ RI $30-69 \%$, and resistance $=\mathrm{RI} \leq 30 \%$ (Chapman et al. 2011). Four replicate plates were tested for each isolate at each dose of difenoconazole and pyraclostrobin. For each isolate, dose response curves were constructed using the relative percent inhibition of colony growth at each logtransformed $\left(\log _{10}\right)$ concentration for the fungicides to determine the value of the effective concentration that inhibited isolate growth by $50 \%\left(\mathrm{EC}_{50}\right)$.

Statistical analysis

Frequencies, means, and standard deviations for difenoconazole and pyraclostrobin $\mathrm{EC}_{50}$ were obtained from raw data. The $\mathrm{EC}_{50}$ value of each isolate was determined by probit analysis with SPSS 21.0. Normality tests were also performed in SPSS 21.0. The Shapiro-Wilk test was used to detect the normality of the data. Kruskal-Wallis tests were used to detect the differences in data in the three regions.

To study cross-resistance, the log-transformed $\mathrm{Ec}_{50}$ values for both fungicides were plotted against each other. Spearman rank correlation tests were also used to analyse the correlation between the two fungicides.

\section{Results}

Sensitivity of $V$. inaequalis isolates to difenoconazole

When $0.05,0.10,0.50$ and $0.10 \mu \mathrm{g} / \mathrm{mL}$ difenoconazole was added to PDA, the mean relative inhibition rates (\%) determined in the 90 isolates of $V$. inaequalis were $14.32,23.37,43.67$ and $54.97 \%$, respectively (Table 2). Table 2 also indicates that the range of $\mathrm{EC}_{50}$ values for the 90 isolates was 0.1431 to $6.735 \mu \mathrm{g} / \mathrm{mL}$, and the average $\mathrm{EC}_{50}$ was $1.464 \mu \mathrm{g} / \mathrm{mL}$, while the ratio of the maximum $\mathrm{EC}_{50}$ to the minimum $\mathrm{EC}_{50}$ was 47.07 . The Shapiro-Wilk test revealed that the data did not conform to a normal distribution ( $\mathrm{W}=0.9595, P<0.05)$ (Fig. 2 , Table 2). Therefore, a nonparametric test was used in the subsequent correlation analysis. 
Table 2 Statistical analysis of the sensitivity of Venturia inaequalis isolates from different regions to difenoconazole

\begin{tabular}{|c|c|c|c|c|c|c|c|c|}
\hline \multirow[t]{3}{*}{ Region of origin } & \multirow[t]{3}{*}{ No. of isolates } & \multicolumn{7}{|c|}{ Difenoconazole } \\
\hline & & \multicolumn{4}{|c|}{$\begin{array}{l}\text { Concentration }(\mu \mathrm{g} / \mathrm{mL}) \text { and } \\
\text { mean relative inhibition rate }{ }^{\mathrm{a}}(\%)\end{array}$} & \multirow[t]{2}{*}{$\begin{array}{l}\text { Range of } \mathrm{EC}_{50} \\
\text { values }(\mu \mathrm{g} / \mathrm{mL})\end{array}$} & \multirow[t]{2}{*}{$\begin{array}{l}\text { Mean } \mathrm{EC}_{50} \\
\text { value }(\mu \mathrm{g} / \mathrm{mL})\end{array}$} & \multirow[t]{2}{*}{ SD } \\
\hline & & 0.05 & 0.10 & 0.50 & 1.00 & & & \\
\hline Shaanxi & 30 & 18.99 & 30.33 & 55.59 & 66.62 & $0.143-4.576$ & 0.768 & 1.245 \\
\hline Gansu & 30 & 13.76 & 19.86 & 35.09 & 47.84 & $0.271-6.735$ & 2.164 & 1.734 \\
\hline Xinjiang & 30 & 6.89 & 27.33 & 42.26 & 71.52 & $0.237-6.206$ & 1.459 & 1.391 \\
\hline Total & 90 & 14.32 & 23.37 & 43.67 & 54.97 & $0.143-6.735$ & 1.464 & 1.563 \\
\hline
\end{tabular}

a: Relative inhibition rate $(\%)=100$ - Relative growth

Sensitivity of $V$. inaequalis isolates to difenoconazole in different regions

The Kruskal-Wallis test indicated significant differences $(P<0.05)$ between the mean $\mathrm{EC}_{50}$ values of the three regions studied. The results showed that the mean $\mathrm{EC}_{50}$ values of the Shaanxi, Gansu and Xinjiang populations were $0.768,2.164$ and 1.459 , respectively, and the mean $\mathrm{EC}_{50}$ value of Gansu was significantly higher $(\mathrm{P}<0.05)$ than that of Shaanxi and Xinjiang (Table 2). However, the ratios of the maximum $\mathrm{EC}_{50}$ to the minimum $\mathrm{EC}_{50}$ in Shaanxi, Gansu and Xinjiang were 31.98, 24.85 and 26.18 , respectively.

Distribution of difenoconazole resistant isolates

Taking the concentration with the largest span of relative inhibition rates as the reference, at a concentration of $0.50 \mu \mathrm{g} / \mathrm{mL}$, resistance, reduced sensitivity and sensitivity to difenoconazole were detected in the study

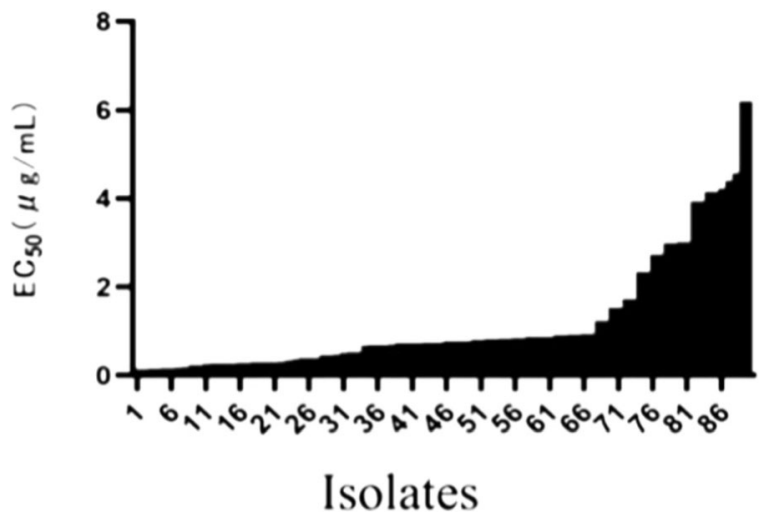

Fig. 2 Distribution of $\mathrm{EC}_{50}$ values of 90 isolates of Venturia inaequalis to difenoconazole in Shaanxi, Gansu and Xinjiang
(Table 3). Among the 90 isolates, $21.1 \%$ were resistant, $73.3 \%$ had reduced sensitivity, and only $5.5 \%$ were sensitive to difenoconazole. In addition, the rates of resistance, reduced sensitivity and sensitivity among isolates to difenoconazole were $6.7 \%, 76.7 \%$, and $16.7 \%$ in Shaanxi, 33.3\%, 66.7\%, and $0 \%$ in Gansu and $23.3 \%, 76.7 \%$, and $0 \%$ in Xinjiang, respectively.

Sensitivity of $V$. inaequalis isolates to pyraclostrobin

With $0.02,0.04,0.20$ and $0.40 \mu \mathrm{g} / \mathrm{mL}$ pyraclostrobin added to PDA, the mean relative inhibition rates (\%) determined in the 90 isolates of $V$. inaequalis were 19.08, 27.71, 42.92 and 55.52, respectively (Table 4). Table 4 indicates that the range of $\mathrm{EC}_{50}$ values in the 90 isolates was 0.084 to $2.026 \mu \mathrm{g} / \mathrm{mL}$, and the average $\mathrm{EC}_{50}$ was $0.438 \mu \mathrm{g} / \mathrm{mL}$, while the ratio of the maximum $\mathrm{EC}_{50}$ to the minimum $\mathrm{EC}_{50}$ was 24.13. The ShapiroWilk test revealed that the data did not conform to a normal distribution ( $\mathrm{W}=0.6625, P<0.05$ ) (Fig. 3, Table 4). Therefore, a nonparametric test was used in the subsequent correlation analysis.

Sensitivity of $V$. inaequalis isolates to pyraclostrobin in different regions

The Kruskal-Wallis test indicated significant differences $(\mathrm{P}<0.05)$ between the mean $\mathrm{EC}_{50}$ values of the three regions studied. The results show that the mean $\mathrm{EC}_{50}$ values of the Shaanxi, Gansu and Xinjiang populations were $0.184,0.738$ and 0.392 , respectively, and the mean $\mathrm{EC}_{50}$ value of the Shaanxi population was significantly lower $(\mathrm{P}<0.05)$ than that of Gansu and Xinjiang (Table 4). In addition, the maximum $\mathrm{EC}_{50}$ value of the Shaanxi population was $0.298 \mu \mathrm{g} / \mathrm{mL}$, which was 
Table 3 Resistance classification of Venturia inaequalis isolates to difenoconazole in Shaanxi, Gansu and Xinjiang determined with a concentration of $0.5 \mu \mathrm{g} / \mathrm{ml}$ fungicide added to media

\begin{tabular}{|c|c|c|c|c|c|c|c|}
\hline \multicolumn{2}{|c|}{ Isolate sampling location } & \multicolumn{6}{|c|}{ Classification of difenoconazole sensitivity ${ }^{\mathrm{a}}$} \\
\hline \multirow[t]{2}{*}{ Region } & \multirow[t]{2}{*}{ County } & \multicolumn{2}{|l|}{ Sensitivity } & \multicolumn{2}{|l|}{ Reduced sensitivity } & \multicolumn{2}{|l|}{ Resistance } \\
\hline & & Number of isolates & $\begin{array}{l}\text { RI }(\%) \\
\text { Mean }\end{array}$ & Number of isolates & $\begin{array}{l}\text { RI }(\%) \\
\text { Mean }\end{array}$ & Number of isolates & $\begin{array}{l}\text { RI }(\%) \\
\text { Mean }\end{array}$ \\
\hline \multirow[t]{3}{*}{ Shaanxi } & Qianyang & 1 & 76.8 & 14 & 55.4 & - & - \\
\hline & Fufeng & 1 & 91.5 & 3 & 41.9 & 2 & 23.9 \\
\hline & Qianxian & 3 & 77.3 & 6 & 53.2 & - & - \\
\hline \multirow[t]{5}{*}{ Gansu } & Jinning & - & - & 7 & 41.3 & 1 & 28.0 \\
\hline & Huining & - & - & 2 & 37.9 & 3 & 23.6 \\
\hline & Lixian & - & - & 3 & 45.2 & 3 & 26.5 \\
\hline & Zhuanglang & - & - & 7 & 39.0 & 1 & 28.6 \\
\hline & Pingliang & - & - & 1 & 35.1 & 2 & 26.3 \\
\hline \multirow[t]{3}{*}{ Xinjiang } & Yining & - & - & 6 & 53.2 & - & - \\
\hline & Gongliu & - & - & 9 & 44.8 & - & - \\
\hline & Tekesi & - & - & 8 & 38.0 & 7 & 28.5 \\
\hline Total & & 5 & 80.0 & 66 & 46.0 & 19 & 26.1 \\
\hline
\end{tabular}

${ }^{\mathrm{a}}$ means Sensitivity $=\mathrm{RI} \geq 70 \%$, Reduced sensitivity $=\mathrm{RI} 30-69 \%$, Resistance $=\mathrm{RI} \leq 30 \%$

'RI' = Relative inhibition rate

significantly lower than that of the Gansu $(1.883 \mu \mathrm{g} /$ $\mathrm{mL})$ and Xinjiang populations $(2.026 \mu \mathrm{g} / \mathrm{mL})$. However, the ratios of the maximum $\mathrm{EC}_{50}$ to the minimum $\mathrm{EC}_{50}$ in Shaanxi, Gansu and Xinjiang were 3.54, 14.37 and 13.83 , respectively.

Distribution of pyraclostrobin resistant isolates

Taking the concentration with the largest span of relative inhibition rates as the reference, at a concentration of $0.20 \mu \mathrm{g} / \mathrm{mL}$, resistance, reduced sensitivity and sensitivity to pyraclostrobin were detected in the study (Table 5). Of the 90 isolates, $8.9 \%$ were resistant, $90.0 \%$ had reduced sensitivity, and only $1.1 \%$ were sensitive to pyraclostrobin. In addition, the rates of resistance, reduced sensitivity and sensitivity among the isolates to pyraclostrobin were $0 \%, 96.7 \%$, and $3.3 \%$ in Shaanxi, 23.3\%, $76.7 \%$, and $0 \%$ in Gansu and 3.3\%, $96.7 \%$, and $0 \%$ in Xinjiang, respectively.

Table 4 Statistical analysis of the sensitivity of Venturia inaequalis isolates from different regions to pyraclostrobin

\begin{tabular}{|c|c|c|c|c|c|c|c|c|}
\hline \multirow{3}{*}{ Region of origin } & \multirow{3}{*}{ No. of isolates } & \multicolumn{7}{|c|}{ Pyraclostrobin } \\
\hline & & \multicolumn{4}{|c|}{$\begin{array}{l}\text { Concentration }(\mu \mathrm{g} / \mathrm{mL}) \text { and mean relative } \\
\text { inhibition } \operatorname{rate}^{\mathrm{a}}(\%)\end{array}$} & \multirow[t]{2}{*}{ Range of $\mathrm{EC}_{50}$ values $(\mu \mathrm{g} / \mathrm{mL})$} & \multirow[t]{2}{*}{$\operatorname{Mean}(\mu \mathrm{g} / \mathrm{mL})$} & \multirow[t]{2}{*}{ SD } \\
\hline & & 0.02 & 0.04 & 0.20 & 0.40 & & & \\
\hline Shaanxi & 30 & 23.49 & 32.76 & 49.66 & 63.47 & $0.084-0.298$ & 0.184 & 0.068 \\
\hline Gansu & 30 & 16.25 & 23.05 & 36.46 & 48.67 & $0.131-1.883$ & 0.738 & 0.579 \\
\hline Xinjiang & 30 & 17.48 & 27.33 & 42.65 & 54.40 & $0.146-2.026$ & 0.392 & 0.370 \\
\hline Total & 90 & 19.08 & 27.71 & 42.92 & 55.52 & $0.084-2.026$ & 0.438 & 0.456 \\
\hline
\end{tabular}

a: Relative inhibition rate $(\%)=100$ - Relative growth 


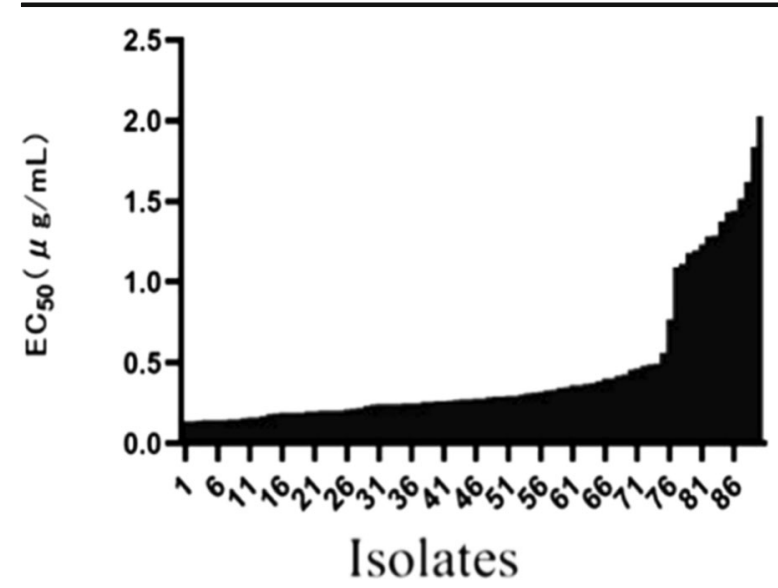

Fig. 3 Distribution of $\mathrm{EC}_{50}$ values of 90 isolates of Venturia inaequalis to pyraclostrobin in Shaanxi, Gansu and Xinjiang

\section{Difenoconazole and pyraclostrobin cross resistance}

The correlation coefficient (R(Angelini et al., 2015)) between the $\log \mathrm{EC}_{50}$ values for difenoconazole and pyraclostrobin was 0.2601 , and the $P$ value was less than 0.0001 . The results of the analysis indicate that there is a weak correlation between difenoconazole and pyraclostrobin (Fig. 4), and a Spearman rank correlation test showed a similar conclusion $\left(R^{2}=0.3198\right.$,

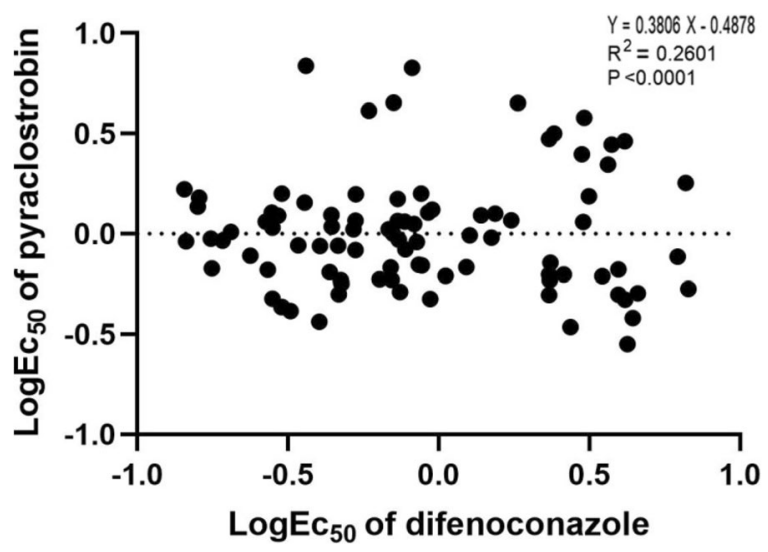

Fig. 4 Scatter gram of pairwise $\log \mathrm{EC}_{50}$ data for difenoconazole and pyraclostrobin

P (two-tailed) <0.001). In addition, four isolates were identified as resistant to both difenoconazole and pyraclostrobin (Table 6).

\section{Discussion}

Our results revealed that the average $\mathrm{EC}_{50}$ value of 90 isolates to difenoconazole was $1.467 \pm 0.017 \mu \mathrm{g} / \mathrm{mL}$,

Table 5 Resistance classification of Venturia inaequalis isolates to pyraclostrobin in Shaanxi, Gansu and Xinjiang determined with a concentration of $0.2 \mu \mathrm{g} / \mathrm{ml}$ fungicide added to media

\begin{tabular}{|c|c|c|c|c|c|c|c|}
\hline \multicolumn{2}{|c|}{ Isolate sampling location } & \multicolumn{6}{|c|}{ Classification of pyraclostrobin sensitivity ${ }^{a}$} \\
\hline \multirow[t]{2}{*}{ Region } & \multirow[t]{2}{*}{ County } & \multicolumn{2}{|l|}{ Sensitivity } & \multicolumn{2}{|l|}{ Reduced sensitivity } & \multicolumn{2}{|l|}{ Resistance } \\
\hline & & Number of isolates & $\begin{array}{l}\text { RI }(\%) \\
\text { Mean }\end{array}$ & Number of isolates & $\begin{array}{l}\text { RI (\%) } \\
\text { Mean }\end{array}$ & Number of isolates & $\begin{array}{l}\text { RI }(\%) \\
\text { Mean }\end{array}$ \\
\hline \multirow[t]{3}{*}{ Shaanxi } & Qianyang & 1 & 72.3 & 14 & 51.9 & - & - \\
\hline & Fufeng & - & - & 6 & 44.7 & - & - \\
\hline & Qianxian & - & - & 9 & 46.5 & - & - \\
\hline \multirow[t]{5}{*}{ Gansu } & Jinning & _- & _ & 7 & 37.8 & 1 & 29.2 \\
\hline & Huining & - & - & 5 & 40.0 & - & - \\
\hline & Lixian & - & - & 2 & 34.5 & 4 & 23.2 \\
\hline & Zhuanglang & _ & _ & 7 & 44.1 & 1 & 26.3 \\
\hline & Pingliang & - & - & 2 & 38.3 & 1 & 29.2 \\
\hline \multirow[t]{3}{*}{ Xinjiang } & Yining & - & - & 6 & 45.2 & - & - \\
\hline & Gongliu & _- & _ & 9 & 45.8 & _- & _- \\
\hline & Tekesi & - & - & 14 & 40.8 & 1 & 24.2 \\
\hline Total & & 1 & 72.3 & 81 & 44.3 & 8 & 24.8 \\
\hline
\end{tabular}

${ }^{\mathrm{a}}$ means Sensitivity $=\mathrm{RI} \geq 70 \%$, Reduced sensitivity $=\mathrm{RI} 30-69 \%$, Resistance $=\mathrm{RI} \leq 30 \%$

'RI' = Relative inhibition rate 
Table 6 Distribution of isolates resistant to difenoconazole and pyraclostrobin or both in Shaanxi, Gansu and Xinjiang

\begin{tabular}{|c|c|c|c|c|}
\hline \multicolumn{2}{|c|}{ Isolate sampling location } & \multicolumn{3}{|c|}{ Resistant isolate to fungicide } \\
\hline Region & County & $\begin{array}{l}\text { Difenoconazole } \\
\text { Number of isolates }\end{array}$ & $\begin{array}{l}\text { Pyraclostrobin } \\
\text { Number of isolates }\end{array}$ & $\begin{array}{l}\text { Both } \\
\text { Number of isolates }\end{array}$ \\
\hline \multirow[t]{3}{*}{ Shaanxi } & Qianyang & - & - & - \\
\hline & Fufeng & 2 & - & - \\
\hline & Qianxian & - & - & - \\
\hline \multirow[t]{5}{*}{ Gansu } & Jinning & 1 & 1 & - \\
\hline & Huining & 3 & - & - \\
\hline & Lixian & 3 & 4 & 3 \\
\hline & Zhuanglang & 1 & 1 & - \\
\hline & Pingliang & 2 & 1 & 1 \\
\hline \multirow[t]{3}{*}{ Xinjiang } & Yining & - & - & - \\
\hline & Gongliu & - & - & - \\
\hline & Tekesi & 7 & 1 & - \\
\hline
\end{tabular}

which is significantly higher than the average $\mathrm{EC}_{50}$ of the baseline population of $V$. inaequalis according to previous reports (Villani et al. 2015; Henríquez Sáez et al., 2011). Based on our results, $73.32 \%$ of 90 isolates had reduced sensitivity to difenoconazole, which implied that application of this fungicide for management of apple scab would lead to decreased control efficiency (Mondino et al. 2015). However, we also found that the $\mathrm{EC}_{50}$ values of all isolates were significantly higher than $0.05 \mu \mathrm{g} / \mathrm{mL}$, the discriminatory dose of difenoconazole, but some apple orchards still achieved satisfactory control of apple scab. A discriminatory dose is a single dose used to classify an isolate as sensitive or resistant to a fungicide, depending upon the reaction of the fungal isolate. Similar reports on DMI fungicides have been made before (Gao et al. 2009). Therefore, judging whether a fungicide is ineffective against a certain pathogen should not be based only on the discriminatory dose. In addition, most of the resistance to DMI fungicides is due to the overexpression of CYP51A1 (Kunz et al. 1997; Stenzel 2014). Resistant individuals did not appear in any orchard that we investigated, indicating that the emergence of resistant isolates was not common, and only individual orchards had a high risk of resistance.

In this study, we found that $8.9 \%$ of isolates were resistant, $90.0 \%$ had reduced sensitivity and $1.1 \%$ were sensitive to pyraclostrobin. Although only 8 isolates of $V$. inaequalis with resistance to pyraclostrobin are present in northwestern China, these isolates are restricted to only some individual areas, orchards or apple plants. We found that many of the isolates examined in this study are not yet completely resistant. Therefore, the potential for the development of practical resistance is largely dependent on continued pyraclostrobin usage.

Pyraclostrobin is one of the QoI fungicides that FRAC has categorized as being at high risk of resistance development. Frequent QoI fungicide usage could create strong selective pressure for resistance because one amino acid switch from glycine to alanine at position 143 (G143A) of the mitochondrial cytochrome b gene can confer high levels of resistance (Wise et al. 2008; Yin et al. 2011; Färber et al. 2002; Olaya et al. 1998), and the paths of QoI resistance can be both quantitative and qualitative (Cox et al. 2008; Köller et al. 2004; Frederick et al. 2014). Moreover, QoI fungicideresistant isolates of $V$. inaequalis can be inherited stably (Feng et al. 2020); thus, once resistant populations of $V$. inaequalis are formed, they cannot be reduced by stopping the application of QoI fungicides.

In addition, we also found that isolates from Shaanxi were more sensitive to the two fungicides than the isolates from Gansu and Xinjiang, which may be because Shaanxi has a longer history of large-scale commercial cultivation of apples than the other two provinces, and growers have better apple orchard management technology and are more reasonable in the application of fungicides in particular.

This study used mycelial growth assays to determine the resistance, reduced sensitivity and sensitivity of 
$V$. inaequalis isolates to difenoconazole and pyraclostrobin fungicides used in commercial apple orchards for the management of apple scab. Mycelial growth assays are labour intensive and time consuming for $V$. inaequalis. However, this method is highly accurate and can easily detect cross resistance between fungicides and find multiple fungicide-resistant isolates. In our study, we found that there was no relationship between these two fungicides by the linear regression method and Spearman rank correlation test. Moreover, isolate resistance to fungicides may also be gained from their enhanced metabolism, which is not conducive to the accumulation of fungicides at the active dose (De Waard and Van Nistelrooy 1979; Zhou and Holomon 1997; Andrade et al. 2000). For this reason, we report that there is no significant correlation between the two fungicides, and they can be used alternately in production.

However, we still found that four isolates were resistant to difenoconazole and pyraclostrobin. The results suggest that isolates with resistance to these two fungicides have appeared in Northwest China, even though these isolates are limited to very few locations. A similar situation was recently reported in North America (Lichtner et al. 2020). Although the probability of multiple fungicide-resistant isolates is very low under natural conditions, a certain fungicide is usually used alone in orchards until control failure occurs; this indicates that the resistant population selected by a given fungicide then undergoes selection by another fungicide, which can easily lead to resistance to multiple fungicides. Therefore, we suggest that it is important to alternate the use of two or more different fungicides for the management of apple scab and try to reduce the usage and times of fungicide application as much as possible during the apple growing season to achieve an acceptable control effect and extend the service life of fungicides.

\section{Conclusion}

This is the first report of the use of a mycelial growth assay to determine difenoconazole and pyraclostrobin resistance levels in $V$. inaequalis populations in Shaanxi, Gansu and Xinjiang, Northwest China. Our results show that the sensitivity of most isolates to these two fungicides is reduced, and isolates resistant to both difenoconazole and pyraclostrobin were found. In recent years, the aggravation of apple scab in Northwest China may have been related to the reduction in population sensitivity to these two fungicides. Although the control effect is still good, the risk of fungicide resistance cannot be ignored. In production, we suggest alternating the use of fungicides with different action mechanisms to prolong their service life.

Acknowledgements This research was supported by the " 111 " Project of the Education Ministry of China (B07049) and the Shaanxi Provincial Science and Technology Project (2015TTCN-10-5).

Authors' contributions All authors performed sample collection. Xiancheng Li, Haiyuan Li and Zhen Yu performed isolation and experiments, particularly Xiancheng Li, who was in charge of the data analysis and writing of the manuscript. Liqiang Gao and Jiarong Yang conceptualized the project and reviewed the manuscript.

Funding This research was funded by the "111" Project of the Education Ministry of China (B07049) and the Shaanxi Provincial Science and Technology Project (2015TTC-N-10-5).

Data availability All data and materials as well as software applications or custom codes support the published claims and comply with field standards.

Code availability Not applicable.

\section{Declarations}

Conflict of interest The authors declare that they have no conflicts of interest.

Ethical approval This article does not contain any studies with human participants or animals performed by any of the authors.

Consent to participate Not applicable.

Consent for publication Not applicable.

Open Access This article is licensed under a Creative Commons Attribution 4.0 International License, which permits use, sharing, adaptation, distribution and reproduction in any medium or format, as long as you give appropriate credit to the original author(s) and the source, provide a link to the Creative Commons licence, and indicate if changes were made. The images or other third party material in this article are included in the article's Creative Commons licence, unless indicated otherwise in a credit line to the material. If material is not included in the article's Creative Commons licence and your intended use is not permitted by statutory regulation or exceeds the permitted use, you will need to obtain permission directly from the copyright holder. To view a copy of this licence, visit http://creativecommons.org/licenses/by/4.0/. 


\section{References}

Andrade, A. C., Del Sorbo, G., Van Nistelrooy, J. G., \& De Waard, M. A. (2000). The ABC transporter AtrB from Aspergillus nidulans mediates resistance to all major classes of fungicides and some natural toxic compounds. Microbiology, 146(8), 1987-1997.

Angelini, R. M. D. M., Pollastro, S., \& Faretra, F. (2015). Genetics of fungicide resistance. In Fungicide Resistance in Plant Pathogens (pp. 13-34). Springer.

Beresford, R. M., \& Manktelow, D. W. L. (1994). Economics of reducing fungicide use by weather-based disease forecasts for control of Venturia inaequalis in apples. New Zelaland Journal of Crop and Horticultural Science., 22, 113-120.

Bowen, J. K., Mesarich, C. H., Bus, V. G., Beresford, R. M., Plummer, K. M., \& Templeton, M. D. (2011). Venturia inaequalis: The causal agent of apple scab. Molecular Plant Pathology, 12(2), 105-122.

Bowyer, P., \& Denning, D. W. (2014). Environmental fungicides and triazole resistance in Aspergillus. Pest Management Science, 70(2), 173-178.

Chapman, K. S., Sundin, G. W., \& Beckerman, J. L. (2011). Identification of resistance to multiple fungicides in field populations of Venturia inaequalis. Plant Disease, 95(8), 921-926.

Cox, K. D., Russo, N. L., Villani, S. M., Parker, D. M., \& Köller, W. (2008). QoI qualitative resistance and CYP51A1 upstream anomalies in NY populations of the apple scab pathogen Venturia inaequalis. Phytopathology, 98, S42.

Cox KD, Villani SM, Ellis MA, Poon CK, Craig-Kuhn MC (2009). Evaluation of fungicides in an orchard with a DMIresistant apple scab population, 2008. Plant Dis Manage Rep PF039.

De Waard, M. A., \& Van Nistelrooy, J. G. M. (1979). Mechanism of resistance to fenarimol in Aspergillus nidulans. Pesticide Biochemistry and Physiology, 10(2), 219-229.

Färber, R. B., Chin, K. M., \& Leadbitter, N. (2002). Sensitivity of Venturia inaequalis to trifloxystrobin. Pest Management Science, 58, 261-267.

Feng, H., Wang, S., Liu, Z., Miao, J., Zhou, M., \& Huang, L. (2020). Baseline sensitivity and resistance risk assessment of Valsa mali to pyraclostrobin. Phytopathology Research, 2(1), $1-8$.

Fontaine, S., Remuson, F., Fraissinet-Tachet, L., Micoud, A., Marmeisse, R., \& Melayah, D. (2009). Monitoring of Venturia inaequalis harbouring the QoI resistance G143A mutation in French orchards as revealed by PCR assays. Pest Management Science, 65, 74-81.

Frederick, Z. A., Villani, S. M., Cooley, D. R., Biggs, A. R., Raes, J. J., \& Cox, K. D. (2014). Prevalence of quinone outside inhibitor resistance and the stability of qualitative QoI resistance in Venturia inaequalis. Plant Disease, 98, 1122-1130.

Gao, L., Berrie, A., Yang, J., \& Xu, X. (2009). Within-and between-orchard variability in the sensitivity of Venturia inaequalis to myclobutanil, a DMI fungicide, in the UK. Pest Management Science, 65(11), 1241-1249.

Golembiewski, R. C., Vargas, J. M., Jones, A. L., \& Detweiler, A. R. (1995). Detection of demethylation inhibitor (DMI) resistance in Sclerotinia homoeocarpa populations. Plant disease (USA)., 79, 491
Henríquez Sáez, J., Sarmiento, O., \& Alarcón, P. (2011). Sensitivity of Venturia inaequalis Chilean isolates to difenoconazole, fenarimol, mancozeb, and pyrimethanil. Chilean Journal of Agricultural Research, 71(1), 39-44.

Holb, I. J., Heijne, B., \& Jeger, M. J. (2003). Summer epidemics of apple scab: The relationship between measurements and their implications for the development of predictive models and threshold levels under different disease control regimes. Journal of Phytopathology, 151(6), 335-343.

Holb, I. J., Heijne, B., Withagen, J. C. M., Gáll, J. M., \& Jeger, M. J. (2005). Analysis of summer epidemic progress of apple scab at different apple production systems in the Netherlands and Hungary. Phytopathology, 95(9), 1001-1020.

Holb, I. J., Abonyi, F., Buurma, J., \& Heijne, B. (2017). On-farm and on-station evaluations of three orchard management approaches against apple scab and apple powdery mildew. Crop Protection, 97, 109-118.

Hu, X., Shutao, Z., \& Yang, J. (2010). Occurrence and research progress on apple scab in China. Chinese Journal of EcoAgriculture, 3, 663-667.

Jobin, T., \& Carisse, O. (2007). Incidence of myclobutanil-and kresoxim-methyl-insensitive isolates of Venturia inaequalis in Quebec orchards. Plant Disease, 91(10), 1351-1358.

Jones, A. L., \& Aldwinckle, H. S. (Eds.). (1990). Compendium of apple and pear diseases. American Phytopathological Society.

Junfei, D., Xusheng, Z., Tongle, H., Shutong, W., Yanan, W., Junyu, Y., \& Keqiang, C. (2012). Efficacy of several fungicides in controlling apple leaf spot and apple ring rot. China Plant Protection, 8, 53-57.

Khajuria, Y. P., Kaul, S., Wani, A. A., \& Dhar, M. K. (2018). Genetics of resistance in apple against Venturia inaequalis (Wint.) Cke. Tree Genetics \& Genomes, 14(2), 1-20.

Köller, W., Parker, D. M., \& Reynolds, K. L. (1991). Baseline sensitivities of Venturia inaequalis to sterol demethylation inhibitors. Plant Disease, 75(7), 726-728.

Köller, W., Wilcox, W. F., Barnard, J., Jones, A. L., \& Braun, P. G. (1997). Detection and quantification of resistance of Venturia inaequalis populations to sterol demethylation inhibitors. Phytopathology, 87(2), 184-190.

Köller, W., Parker, D. M., Turechek, W. W., Avila-Adame, C., \& Cronshaw, K. (2004). A two-phase resistance response of Venturia inaequalis populations to the QoI fungicides kresoxim-methyl and trifloxystrobin. Plant Disease, 88(5), 537-544.

Kunz, S., Deising, H., \& Mendgen, K. (1997). Acquisition of resistance to sterol demethylation inhibitors by populations of Venturia inaequalis. Phytopathology, 87(12), 1272-1278.

Lesniak, K., Proffer, T., Beckerman, J., \& Sundin, G. (2011). Occurrence of QoI resistance and detection of the G143A mutation in Michigan populations of Venturia inaequalis. Plant Disease, 95, 927-934.

Lichtner, F. J., Jurick, W. M., Ayer, K. M., Gaskins, V. L., Villani, S. M., \& Cox, K. D. (2020). A genome resource for several north American Venturia inaequalis isolates with multiple fungicide resistance phenotypes. Phytopathology, 110(3), 544-546.

MacHardy, W. E. (1996). Apple scab: Biology, epidemiology, and management. American Phytopathological Society (APS Press). 
MacHardy, W. E., \& Gadoury, D. M. (1989). A revision of Mills's criteria for predicting apple scab infection periods. Phytopathology, 79, 304-310.

McClure, K. A., Gardner, K. M., Douglas, G. M., Song, J., Forney, C. F., DeLong, J., Fan, L., du, L., Toivonen, P. M. A., Somers, D. J., Rajcan, I., \& Myles, S. (2018). A genomewide association study of apple quality and scab resistance. The plant genome, 11(1), 170075.

Mondino, P., Casanova, L., Celio, A., Bentancur, O., Leoni, C., \& Alaniz, S. (2015). Sensitivity of Venturia inaequalis to Trifloxystrobin and Difenoconazole in Uruguay. Journal of Phytopathology, 163(1), 1-10.

Olaya, G., Zheng, D., \& Köller, W. (1998). Differential responses of germinating Venturia inaequalis conidia to kresoximmethyl. Pesticide Science, 54(3), 230-236.

Papp, D., Gao, L., Thapa, R., Olmstead, D., \& Khan, A. (2020). Field apple scab susceptibility of a diverse Malus germplasm collection identifies potential sources of resistance for apple breeding. CABI Agriculture and Bioscience, 1(1), 1-14.

Passey, T. A. J., Shaw, M. W., \& Xu, X. M. (2016). Differentiation in populations of the apple scab fungus Venturia inaequalis on cultivars in a mixed orchard remain over time. Plant Pathology, 65(7), 1133-1141.

Pfeufer, E. E., \& Ngugi, H. K. (2012). Orchard factors associated with resistance and cross resistance to sterol demethylation inhibitor fungicides in populations of Venturia inaequalis from Pennsylvania. Phytopathology, 102(3), 272-282.

Stanis, V. F., \& Jones, A. L. (1985). Reduced sensitivity to sterolinhibiting fungicides in field isolates of Venturia inaequalis. Phytopathology, 75(10), 1098-1101.

Steinfeld U., Sierotzki H., Parisi S. and Gisi U. (2002). Comparison of resistance mechanisms to strobilurin fungicides in Venturia inaequalis. In: Modern fungicides and antifungal compounds II, eds Lyr H., Russell P. E., Dehne H-W. Gisi U. Kuck K-H, 13th International Reinhardsbrunn Symposium, AgroConcept, Bonn, Verlag Th. Mann Gelsenkirchen, pp. 167-176.

Stenzel, K. (2014). FRAC SBI working group. Online publication http://www.frac.info/working-group/sbi-fungicides.

Villani, S. M., \& Cox, K. D. (2011). Characterizing fenbuconazole and propiconazole sensitivity and prevalence of 'Mona' in isolates of Monilinia fructicola from New York. Plant Disease, 95(7), 828-834.

Villani, S. M., \& Cox, K. D. (2014). Heteroplasmy of the cytochrome b gene in Venturia inaequalis and its involvement in quantitative and practical resistance to trifloxystrobin. Phytopathology, 104, 945-953.

Villani, S. M., Biggs, A. R., Cooley, D. R., Raes, J. J., \& Cox, K. D. (2015). Prevalence of myclobutanil resistance and difenoconazole insensitivity in populations of Venturia inaequalis. Plant Disease, 99(11), 1526-1536.

Wise, K. A., Bradley, C. A., Pasche, J. S., Gudmestad, N. C., Dugan, F. M., \& Chen, W. (2008). Baseline sensitivity of Ascochyta rabiei to azoxystrobin, pyraclostrobin, and boscalid. Plant Disease, 92, 295-300.

Yin, Y. N., Kim, Y. K., \& Xiao, C. L. (2011). Molecular characterization of boscalid resistance in field isolates of Botrytis cinerea from apple. Phytopathology, 101, 986-995.

Ypema, H. L., \& Gold, R. E. (1999). Kresoxim-methyl: Modification of a naturally occurring compound to produce a new fungicide. Plant Disease, 83, 4-19.

Zhou, M. G., \& Holomon, D. W. (1997). Molecular mechanism of resistance of Neurospora Crassa to triadimenol. Acta Phytopathologica Sinica, 27(3), 281-285. 